\title{
Investigation on knowledge, attitudes and practices about food safety and nutrition in the China during the epidemic of corona virus disease 2019
}

\author{
Yingyi Luo, Linjun Chen, Fei Xu, Xiaoxia Gao, Dan Han and Lixin Na* \\ Shanghai University of Medicine \& Health Sciences, 279 Zhouzhu Road, Pudong New Area, Shanghai, People's \\ Republic of China
}

Submitted 24 March 2020: Final revision received 8 July 2020: Accepted 13 July 2020: First published online 16 July 2020

\begin{abstract}
Objective: To investigate the knowledge, attitudes and practices (K-A-P) about food safety and nutrition in Chinese adults who were recruited to the online survey during the epidemic of corona virus disease 2019 (COVID-19).

Design: Participants were recruited by an online snowball sampling method. An electronic questionnaire was sent to our colleagues, students, friends, other professionals and their referrals helped us recruit more participants. The questionnaire included socio-demographic information, the attention paid to COVID-19, $\mathrm{K}-\mathrm{A}-\mathrm{P}$ about food safety and nutrition. Multiple and logistic regression analyses were used to explore related factors of K-A-P.

Subjects: Totally, 2272 participants aged 24.09 $\pm 9 \cdot 14$ years, from twenty-seven provinces, autonomous districts or municipalities, with $18.3 \%$ male and $83.4 \%$ with a medical background.

Results: The total possible knowledge score was 8.0 , the average score was $5.2 \pm 1.6$ and $4.2 \%$ obtained 8.0 . The total possible attitudes score was $8 \cdot 0$, the average score was $6 \cdot 5 \pm 1.4$ and $36 \cdot 1 \%$ obtained $8 \cdot 0$. The total possible food safety practices score was $5 \cdot 0$, the average score was $3.7 \pm 1 \cdot 0$ and $20.7 \%$ obtained $5 \cdot 0$. During this public emergency, $79.4 \%$ participants changed diet habits, including increasing vegetables, fruit and water intake and reducing sugary drinks and snacks. Gender, age, educational and professional background, disease history, the attention paid to COVID-19 and related knowledge were associated with K-A-P. Conclusion: There was room for the improvement of K-A-P in participants during this public health emergency and further strengthening education about food safety and nutrition is needed. Findings indicate that education should address biased or misleading information and promote nutritious food choices and safe food practices.
\end{abstract}

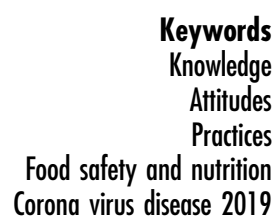

Keywords

Knowledge

Attitudes

Practices

Corona virus disease 2019
At the beginning of 2020, there was an outbreak of pneumonia caused by novel coronavirus infection in China, which seriously affected the normal work and life of residents and posed a serious threat to people's health ${ }^{(1,2)}$. Virus virulence, personal susceptibility and immunity are the key determinants of the disease during the exposure to the novel coronavirus virus ${ }^{(3)}$. Good personal nutrition condition can reduce the risk of infection and improve the prognosis of the disease ${ }^{(4)}$. The Chinese Nutrition Society and the Chinese Medical Association announced a series of dietary nutrition recommendations and guidelines for the prevention and treatment of the corona virus disease 2019 (COVID-19) $^{(5-7)}$. Nutrition experts in China have also carried out timely food safety and nutrition education on various platforms and media, hoping to draw attention to food safety, nutrition and a healthy lifestyle $\mathrm{e}^{(8,9)}$. The purpose of this study is to investigate the knowledge, attitudes and practices (K-A-P) about food safety and nutrition in Chinese adults who were recruited to the online survey during the outbreak period of COVID-19 and to explore the necessity and feasible measures to promote the application of relevant professional knowledge during public health emergencies. 


\section{Methods}

\section{Participants}

People at all levels of the society, aged 18 years or above, who were volunteering to participate in the survey were eligible in this study. An electronic questionnaire was designed to obtain information from the participants in terms of 'Questionnaire Star' which is a mobile app for online questionnaire. On the first page of the questionnaire, there was an informed consent of this survey. Each participant could not fill in the online questionnaire until he has marked 'agree' to the informed consent. Subjects who were invited but not willing to participant the survey, they just needed to mark 'disagree' and then they would leave the 'Questionnaire Star'. Participants were recruited by an online snowball sampling method. The link of 'Questionnaire Star' was sent to our colleagues, students, friends, other professionals and their referrals helped us recruit more participants. This study was approved by the ethics committee of 'Shanghai University of Medicine and Health Sciences'.

\section{Questionnaire}

The questionnaire was designed by ourselves, and the contents, structure and logicality of the questionnaire were discussed by experts in nutrition and epidemiology. Among the WeChat contacts of investigation group members, thirty people were selected for pre-investigation, and a repeated investigation was made 1 week later, with the reliability coefficient $r=0.886$. The first part of the questionnaire was general information, including gender, age, education background, profession/specialty, place of residence and disease history. The second part was the participants' attention paid to information about COVID-19, including the way (Four choices: the mainstream media; the official account; various news clients and WeChat/personal microblog), frequency and duration of attention to the epidemic (Seven choices: basically not involved; 3-5 times/week, $<20 \mathrm{~min} /$ time; every day and $<20 \mathrm{~min} / \mathrm{d}$; every day and $20-40 \mathrm{~min} / \mathrm{d}$; every day and 40-60 min/d; every day and 1-2 h/d; every day and more than $2 \mathrm{~h} / \mathrm{d}$ ) and the way to obtain knowledge about nutrition and immunity. (Three choices: no attention; passively received form the news media or others; active obtaining information such as searching from internet or books.) The participants gave the answers based on the choices in the online questionnaire. The third part was about K-A-P of food safety and nutrition during the epidemic, and all the information was collected by multiple choice questions. In the knowledge part, eight questions were asked to assess the participants' nutrition knowledge. Scores were calculated as 1 point for each correct answer and 0 for error choices. In the attitudes part, eight questions were asked to assess food safety and nutrition attitudes. There were two choices for each question, 'yes' and 'no' representing positive and negative attitudes, respectively. Scores were calculated as 1 point for each 'yes' and 0 for 'no'. In the practices part, there were five questions about food safety practices and twenty questions about diet habit changes practices during the outbreak of COVID-19. For food safety practices, the participants were asked if they always or often cook at home, eat raw food, extend the meat cooking time, regular disinfection of kitchen utensils and eat separate dishes among family members during the outbreak of COVID19. The answers to the five questions about food safety practices were 'yes' or 'no' and 1 point for 'yes' and 0 for 'no'. For diet habit changes, the participants were asked to recall their diet changes in twenty common food category intakes, compared with the same period of last year (Chinese Spring Festival). The answers to each question were 'increased', 'unchanged' or 'decreased', which were calculated as 1, 0 or -1 point, respectively. The score of diet habit changes was calculated as the sum of absolute values. If the participants chose 'increased' or 'decreased' for one food category, they will further be asked to select the reason including restricted food materials by the COVID-19 epidemic or active change to prevent COVID-19.

\section{Data collection}

From 19:00, 26 February 2020 to 12:00, 29 February 2020, the online survey was conducted using the network convenient snowball sampling method in terms of questionnaire star. The participants filled in the questionnaire anonymously. The same IP address could only be used once to respond to the survey request. The questionnaire could not be submitted until all questions were completed. At the same time, background monitoring was performed to ensure the reliability of the data.

\section{Statistical analysis}

SPSS 22.0 was used for statistical analysis. The category variables were expressed as frequency (percentage) and numerical variables as mean $\pm \mathrm{SD}$. Multiple regression analysis was used to explore the factors that were associated with food safety and nutrition K-A-P. Age, gender, educational background, medical background, medical history, attention to COVID-19, attention to nutrition and immunity knowledge, and place of residence during COVID-19 outbreak were explored as associated factors of K-A-P and taken into the models as independent variables. Logistic regression analysis was used to analyse the associated factors of diet habit changes. Diet habit change scores (two classification based on the median of the score 5: $1=$ diet habit change score $<5,2=$ diet habit change score $\geq 5$ ) were taken as the dependent variable in the models and age, gender, education, medical history, place of residence, whether medical background and other factors such as attention to the COVID-19 epidemic and nutrition knowledge were adjusted. A two-sided $P<0.05$ was considered statistically significant. 
Table 1 Basic characteristics of the participants $(n$ 2272)

\begin{tabular}{|c|c|c|}
\hline Variable & $n$ & $\begin{array}{l}\text { Proportion } \\
\quad(\%)\end{array}$ \\
\hline \multicolumn{3}{|l|}{ Age distribution } \\
\hline $18-$ & 2184 & $78 \cdot 8$ \\
\hline 25- & 518 & $18 \cdot 7$ \\
\hline $50-$ & 70 & 2.5 \\
\hline \multicolumn{3}{|l|}{ Gender } \\
\hline Male & 507 & $18 \cdot 3$ \\
\hline Female & 2265 & $81 \cdot 7$ \\
\hline \multicolumn{3}{|l|}{ Education background } \\
\hline Elementary, middle, and high school & 165 & $6 \cdot 0$ \\
\hline Associate degree & 975 & 34.5 \\
\hline Bachelor degree & 1416 & $51 \cdot 1$ \\
\hline Master degree and above & 234 & 8.4 \\
\hline \multicolumn{3}{|l|}{ With medical background or not } \\
\hline Yes & 2313 & $83 \cdot 4$ \\
\hline No & 459 & $16 \cdot 6$ \\
\hline \multicolumn{3}{|l|}{ Disease history } \\
\hline Yes & 193 & $7 \cdot 0$ \\
\hline No & 2579 & $93 \cdot 0$ \\
\hline \multicolumn{3}{|l|}{ Attention to COVID-19 } \\
\hline Basically not involved & 70 & 2.5 \\
\hline $\begin{array}{l}3-5 \text { times a week, within } 20 \text { min each } \\
\text { time }\end{array}$ & 893 & $32 \cdot 2$ \\
\hline$<20 \mathrm{~min} / \mathrm{d}$ & 795 & $28 \cdot 7$ \\
\hline $20-40 \mathrm{~min} / \mathrm{d}$ & 478 & $17 \cdot 2$ \\
\hline $40-60 \mathrm{~min} / \mathrm{d}$ & 171 & $6 \cdot \overline{2}$ \\
\hline $1-2 \mathrm{~h} / \mathrm{d}$ & 199 & $7 \cdot 2$ \\
\hline More than $2 \mathrm{~h} / \mathrm{d}$ & 166 & $6 \cdot 0$ \\
\hline \multicolumn{3}{|l|}{$\begin{array}{l}\text { Attention to nutrition and immunity } \\
\text { knowledge }\end{array}$} \\
\hline $\begin{array}{l}\text { knowledge } \\
\text { No attention }\end{array}$ & 736 & $26 \cdot 6$ \\
\hline Passive attention & 1656 & 59.7 \\
\hline Active attention & 380 & $13 \cdot 7$ \\
\hline \multicolumn{3}{|l|}{$\begin{array}{l}\text { Place of residence during COVID-19 } \\
\text { outbreak }\end{array}$} \\
\hline First-tier cities & 1171 & 53.7 \\
\hline Other cities & 1071 & $46 \cdot 3$ \\
\hline
\end{tabular}

\section{Results}

\section{Basic characteristics of the subjects}

A total of 2772 eligible participants were included in this survey, including 507 male (18.3\%) and 2265 female ( $81.7 \%)$. The participants came from twenty-seven provinces, autonomous districts or municipalities of China with an average age of $24.09 \pm 9 \cdot 14$ years. Basic characteristics of the participants are shown in Table 1 . The proportion of participants aged 18-25 years was $78.8 \%$, and there were $18.7 \%$ aged $25-50$ years. Among the participants, $59.5 \%$ had a bachelor's degree or over, and $83.4 \%$ had a medical background. During the COVID-19 epidemic period, $53.7 \%$ of the participants lived in first-tier cities such as Beijing, Shanghai and Guangzhou and $46.3 \%$ in other areas. There were $7 \%$ participants who had the history of CVD and cerebrovascular diseases, diabetes, hypertension, cancer or other chronic diseases.

The participants obtained information about the COVID-19 epidemic situation through diversified channels, $87 \cdot 2 \%$ from the official microblog/WeChat/official account, $74.0 \%$ from the mainstream media through The Xinhua news Agency/CCTV/People's Daily and 66.3\% from the news push through various news clients and WeChat/personal microblog. The frequency and duration of attention were mostly 3-5 times per week, within $20 \mathrm{~min}$ each time and every day and $<20 \mathrm{~min} / \mathrm{d}$ on average, accounting for $32.2 \%$ and $28.7 \%$ of the total participants, respectively. During the COVID-19 epidemic period, $73.4 \%$ participants paid attention to nutrition and immunity-related knowledge. Among them, 59.7\% passively received through news media or others, and $13.7 \%$ actively acquired through their own access to information by Internet or books.

\section{Awareness rate of nutrition knowledge and its related factors}

The total possible score of this part was 8 , and the average score was $5 \cdot 21 \pm 1 \cdot 57$. There were $70 \cdot 1 \%$ participants who answered half of the questions or more correctly and $4.2 \%$ obtained 8 . They generally had a relatively good understanding of the Chinese balanced diet guidelines and dietary pagoda, nutrition labels, nutrition characteristics of food and other basic knowledge (Fig. 1). The awareness rate of daily salt intake limit and immunity-related nutrients was relatively low, $<50 \%$. Multiple regression analysis showed that the nutrition knowledge scores were associated with gender, educational background, occupational background, degree of attention paid to the COVID-19 epidemic, degree of attention paid to nutrition and immunity-related knowledge and place of residence (Table 2). Women's understanding of nutrition knowledge was better than that of men. Participants with higher education, medical background, living in first-tier cities and paying more attention to epidemic situation, nutrition and immunity knowledge were more likely to get higher scores $(P<0.05)$.

\section{Food safety and nutrition attitudes of the participants and its related factors}

The total possible score of this part was 8 , and the average score was $6 \cdot 52 \pm 1 \cdot 41$, among whom $36 \cdot 1 \%$ obtained 8 . Among the eight questions, there were five closely related to the COVID-19 epidemic, and 63.3\% participants chose a positive attitude for all the five questions (Fig. 2). The total attitudes scores were related to gender, age, educational background, the degree of attention paid to the epidemic situation and the degree of attention paid to the knowledge related to nutrition and immunity (Table 3 ). With the increase of age, participants were more likely to have positive attitudes towards food safety and nutrition, and women's attitudes towards food safety and nutrition were generally more positive than that of men. Participants, who were highly educated, paid more attention to epidemic, nutrition and immunity-related knowledge and 


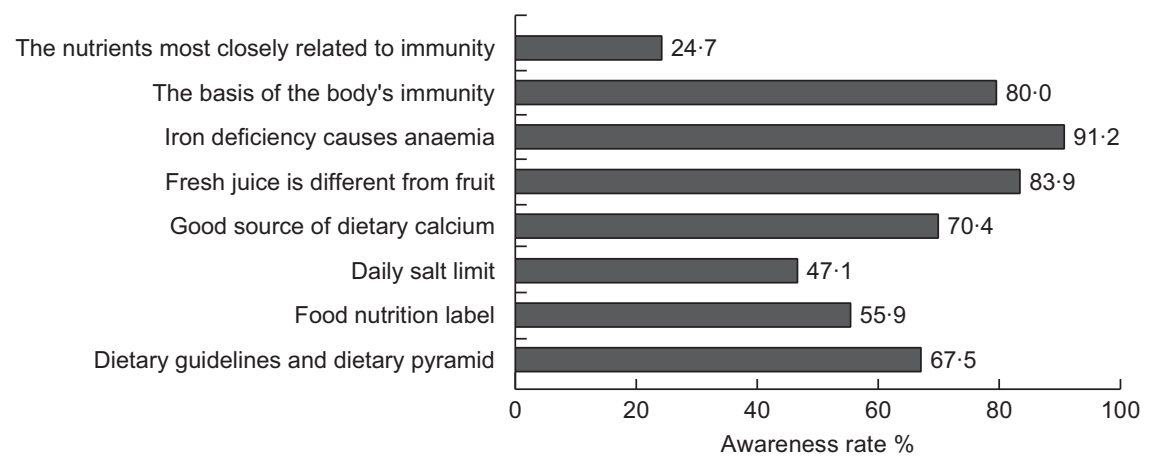

Fig. 1 Awareness rate of nutrition knowledge among the participants ( $n$ 2772)

Table 2 Multiple regression analysis on associated factors of nutritional knowledge score

\begin{tabular}{|c|c|c|c|}
\hline Variable & $\begin{array}{c}\beta \\
\text { value }\end{array}$ & $\begin{array}{l}\text { Standard } \beta \\
\text { value }\end{array}$ & $\begin{array}{c}P \\
\text { value }\end{array}$ \\
\hline Age & -0.001 & -0.005 & 0.846 \\
\hline \multicolumn{4}{|l|}{ Gender } \\
\hline Male & - & - & - \\
\hline Female & 0.261 & 0.064 & 0.001 \\
\hline \multicolumn{4}{|l|}{ Education background } \\
\hline High school or below & - & - & - \\
\hline Associate degree & 0.379 & 0.115 & 0.006 \\
\hline Bachelor degree & 0.440 & 0.140 & 0.001 \\
\hline Master degree and above & 0.735 & 0.130 & $<0.001$ \\
\hline \multicolumn{4}{|l|}{ With medical background or not } \\
\hline No & _- & - & _- \\
\hline Yes & 0.445 & 0.105 & $<0.001$ \\
\hline \multicolumn{4}{|l|}{ Medical history } \\
\hline No & - & _ & - \\
\hline Yes & -0.200 & -0.032 & 0.093 \\
\hline \multicolumn{4}{|l|}{ Attention to COVID-19 } \\
\hline Basically not involved & - & - & - \\
\hline $3-5$ times/week, $<20 \mathrm{~min} / \mathrm{time}$ & 0.574 & $0 \cdot 171$ & 0.002 \\
\hline$<20 \mathrm{~min} / \mathrm{d}$ & 0.758 & 0.218 & $<0.001$ \\
\hline $20-40 \mathrm{~min} / \mathrm{d}$ & 0.786 & 0.189 & $<0.001$ \\
\hline $40-60 \mathrm{~min} / \mathrm{d}$ & 0.753 & 0.115 & $<0.001$ \\
\hline $1-2 \mathrm{~h} / \mathrm{d}$ & 0.641 & 0.105 & 0.002 \\
\hline More than $2 \mathrm{~h} / \mathrm{d}$ & 0.652 & 0.099 & 0.002 \\
\hline \multicolumn{4}{|l|}{$\begin{array}{l}\text { Attention to nutrition and } \\
\text { immunity knowledge }\end{array}$} \\
\hline No attention & - & - & _- \\
\hline Passive attention & 0.645 & 0.202 & $<0.001$ \\
\hline & 0.843 & 0.185 & $<0.001$ \\
\hline \multicolumn{4}{|l|}{ Place of residence during } \\
\hline COVID-19 outbreak & & & \\
\hline First-tier cities & - & - & - \\
\hline Other cities & -0.416 & -0.132 & $<0.001$ \\
\hline
\end{tabular}

were more likely to have positive attitudes towards food safety and nutrition $(P<0.05)$.

\section{Food safety and nutrition practices and its related factors}

The total possible score of food safety was 5 , the average score was $3.69 \pm 0.96$ and $20.7 \%$ obtained 5 . The proportion of always or often cooking at home, not eating raw food, extending meat cooking time and regular disinfection of kitchen utensils was 96.0 \%, 88.2\%, 84.2\% and 68.0\%, respectively. But the proportion of eating separate dishes among family members was only $32 \cdot 5 \%$. Food safety practices were related to age, education background, disease history, degree of attention paid to epidemic situation, degree of attention paid to nutrition and immunity-related knowledge and place of residence (Table 4). With the increase of age, people were more likely to choose safe dietary practices and having disease history, paying more attention to epidemic situation, nutrition and immunityrelated knowledge and living in the first-tier cities were associated with relatively safe dietary practices $(P<0.05)$. Participants with a bachelor's degree or above had lower food safety practices scores than those with high school degree or below, although they had higher scores of knowledge and attitudes on food safety and nutrition $(P<0.05)$.

According to their memory, $79.4 \%$ participants changed their diet habits during the COVID-19 epidemic period, when compared with the same period in last year (Chinese Spring Festival). Among the twenty common food categories, the top ten food categories with increased or decreased intakes by the participants during the COVID19 epidemic period and the reasons are shown in Figs 3 and 4 . Among the food categories with increased intakes by the participants, vegetables, water, tea and coffee, fruit and whole grain were most common, with a proportion over $20 \%$ for each category. The main reason for the increase in vegetables, water, tea and coffee and fruit intakes was active change of their diet habits to prevent COVID-19, with the proportions of $68.3 \%, 81.9 \%$ and $78.9 \%$ for each category, respectively. Among the food categories with decreased intakes by the participants, sea cucumber, fish shrimp and crab, poultry meat, livestock meat, sugary drinks and snacks were most common, with a proportion over $20 \%$ for each category. The proportion of active decrease in sugary drinks and snacks was over $50 \%$, while the reason for decrease in other food categories was both active change and restriction of food materials by COVID-19.

Multiple logistic regression showed that participants with elder age, paying more attention to nutrition and 


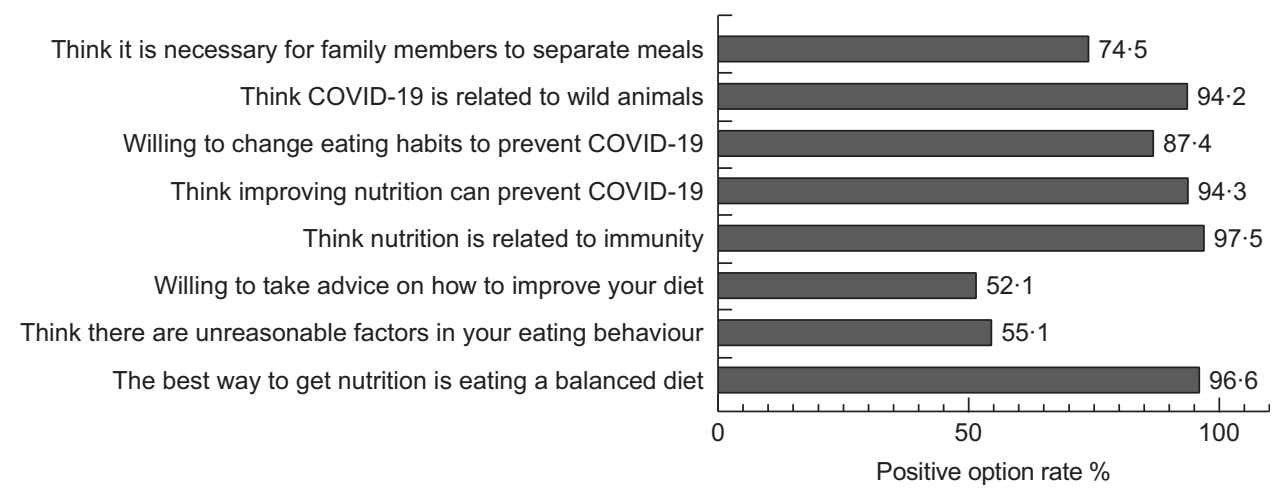

Fig. 2 Food safety and nutrition attitudes $v$. option rate among the participants $(n 2772)$

Table 3 Multiple regression analysis of associated factors of food safety and nutrition attitudes score

\begin{tabular}{|c|c|c|c|}
\hline Variable & $\begin{array}{c}\beta \\
\text { value }\end{array}$ & $\begin{array}{l}\text { Standard } \beta \\
\text { value }\end{array}$ & $\begin{array}{c}P \\
\text { value }\end{array}$ \\
\hline Age & 0.012 & 0.080 & 0.005 \\
\hline \multicolumn{4}{|l|}{ Gender } \\
\hline Male & - & - & - \\
\hline Female & 0.205 & 0.056 & 0.004 \\
\hline \multicolumn{4}{|l|}{ Education background } \\
\hline High school or below & - & - & - \\
\hline Associate degree & 0.302 & $0 \cdot 102$ & 0.018 \\
\hline Bachelor degree & 0.289 & 0.103 & 0.017 \\
\hline Master degree and above & 0.472 & 0.093 & 0.001 \\
\hline \multicolumn{4}{|l|}{ With medical background or not } \\
\hline No & - & - & - \\
\hline Yes & -0.126 & -0.033 & 0.164 \\
\hline \multicolumn{4}{|l|}{ Medical history } \\
\hline No & - & - & - \\
\hline Yes & 0.072 & 0.013 & 0.518 \\
\hline \multicolumn{4}{|l|}{ Attention to COVID-19 } \\
\hline Basically not involved & - & - & - \\
\hline 3-5 times/week, $<20 \mathrm{~min} /$ time & 0.509 & 0.169 & 0.003 \\
\hline$<20 \mathrm{~min} / \mathrm{d}$ & 0.589 & $0 \cdot 189$ & 0.001 \\
\hline $20-40 \mathrm{~min} / \mathrm{d}$ & 0.645 & $0 \cdot 173$ & $<0.001$ \\
\hline $40-60 \mathrm{~min} / \mathrm{d}$ & 0.871 & $0 \cdot 148$ & $<0.001$ \\
\hline $1-2 \mathrm{~h} / \mathrm{d}$ & 0.791 & 0.145 & $<0.001$ \\
\hline More than $2 \mathrm{~h} / \mathrm{d}$ & 0.551 & 0.093 & 0.006 \\
\hline \multicolumn{4}{|l|}{$\begin{array}{l}\text { Attention to nutrition and } \\
\text { immunity knowledge }\end{array}$} \\
\hline No attention & - & - & - \\
\hline Passive attention & 0.255 & 0.089 & $<0.001$ \\
\hline Active attention & 0.244 & 0.060 & 0.006 \\
\hline \multicolumn{4}{|l|}{ Place of residence during } \\
\hline \multicolumn{4}{|l|}{ COVID-19 outbreak } \\
\hline First-tier cities & - & - & - \\
\hline Other cities & 0.089 & 0.031 & $0 \cdot 100$ \\
\hline
\end{tabular}

immunity-related knowledge and living in cities other than the first-tier cities were more likely to change dietary habits (Table 5). Food safety practices score was significantly associated with food change practices, OR $=1.204$ (95\% CI: $1 \cdot 105,1 \cdot 312)$, adjusted for age, gender, education, medical history, place of residence, whether medical background and other factors such as attention paid to the COVID-19 epidemic and nutrition knowledge. People with higher scores on food safety practices tended to change or adjust their diet habits during the COVID-19 epidemic period.
Table 4 Multiple regression analysis of associated factors of food safety practices score

\begin{tabular}{|c|c|c|c|}
\hline Variable & $\begin{array}{c}\beta \\
\text { value }\end{array}$ & $\begin{array}{l}\text { Standard } \beta \\
\text { value }\end{array}$ & $\begin{array}{c}P \\
\text { value }\end{array}$ \\
\hline Age & -0.008 & -0.080 & 0.003 \\
\hline \multicolumn{4}{|l|}{ Gender } \\
\hline Male & - & - & - \\
\hline Female & -0.015 & -0.006 & 0.749 \\
\hline \multicolumn{4}{|l|}{ Education background } \\
\hline High school or below & _ & _ & _ \\
\hline Associate degree & -0.132 & -0.066 & 0.110 \\
\hline Bachelor degree & -0.239 & -0.125 & 0.002 \\
\hline Master degree and above & -0.505 & -0.147 & $<0.001$ \\
\hline \multicolumn{4}{|l|}{ With medical background or not } \\
\hline No & - & - & - \\
\hline Yes & 0.110 & 0.043 & 0.060 \\
\hline \multicolumn{4}{|l|}{ Medical history } \\
\hline No & - & - & - \\
\hline Yes & -0.236 & -0.063 & 0.001 \\
\hline \multicolumn{4}{|l|}{ Attention to COVID-19 } \\
\hline Basically not involved & - & - & - \\
\hline 3-5 times/week, $<20 \mathrm{~min} /$ time & 0.259 & 0.126 & 0.022 \\
\hline$<20 \mathrm{~min} / \mathrm{d}$ & 0.308 & 0.146 & 0.006 \\
\hline $20-40 \mathrm{~min} / \mathrm{d}$ & 0.385 & 0.152 & 0.001 \\
\hline $40-60 \mathrm{~min} / \mathrm{d}$ & 0.308 & 0.077 & 0.017 \\
\hline $1-2 \mathrm{~h} / \mathrm{d}$ & 0.454 & 0.123 & $<0.001$ \\
\hline More than $2 \mathrm{~h} / \mathrm{d}$ & 0.422 & 0.105 & 0.001 \\
\hline \multicolumn{4}{|l|}{$\begin{array}{l}\text { Attention to nutrition and } \\
\text { immunity knowledge }\end{array}$} \\
\hline No attention & _- & _ & _ \\
\hline Passive attention & 0.554 & 0.284 & $<0.001$ \\
\hline Active attention & 0.549 & 0.198 & $<0.001$ \\
\hline \multicolumn{4}{|l|}{ Place of residence during } \\
\hline \multicolumn{4}{|l|}{ COVID-19 outbreak } \\
\hline First-tier cities & - & - & - \\
\hline Other cities & -0.124 & -0.065 & $<0.001$ \\
\hline
\end{tabular}

\section{Discussion}

This study investigated the food safety and nutrition K-A-P of Chinese residents and associated factors during the COVID-19 epidemic. The participants generally paid attention to the epidemic situation and related information. They had a relatively good K-A-P about food safety and nutrition, but there was still room for the improvement of K-A-P. Gender, age, educational background, occupational 

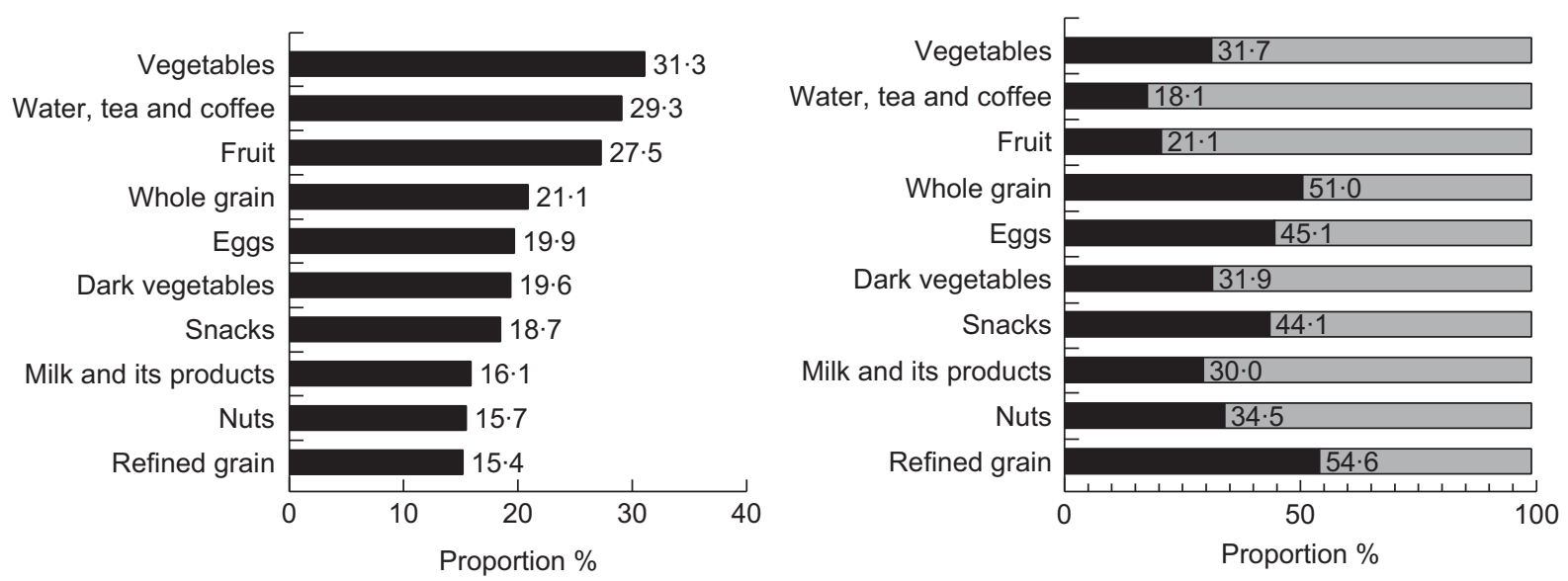

Fig. 3 The top ten food categories with increased intakes by the participants and reasons provided. Left. $\square$, The top ten food categories with decreased intakes by participants. Right: $\square$, restricted food materials by COVID-19; active change to prevent COVID-19
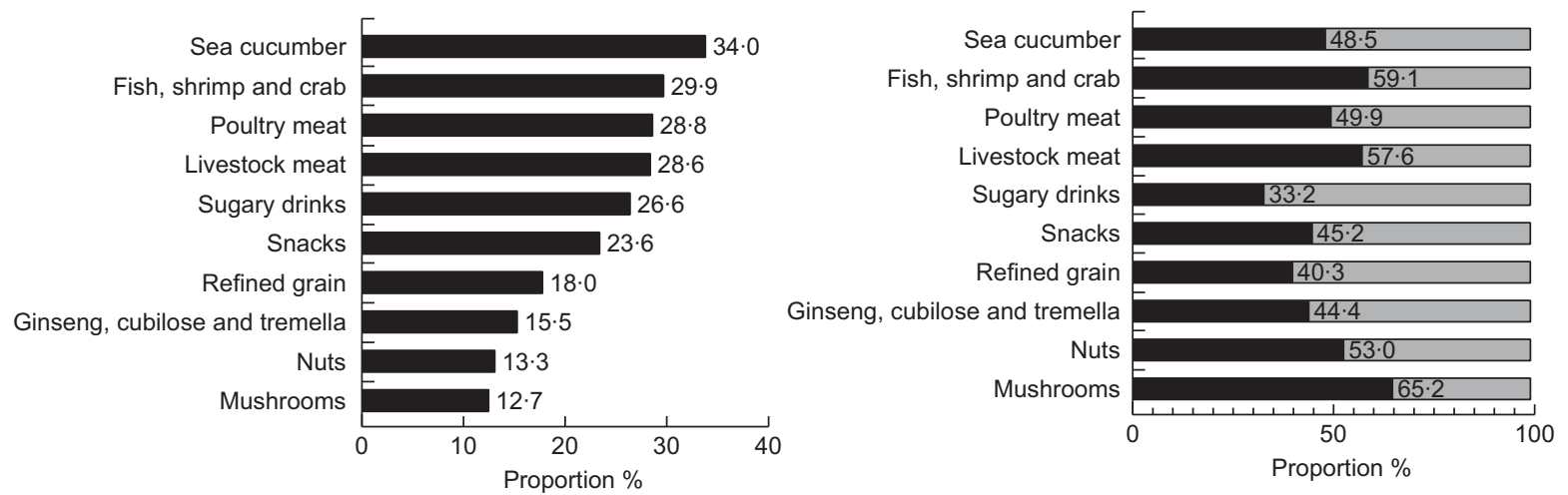

Fig. 4 The top ten food categories with decreased intakes by the participants and reasons provided. Left: $\mathbf{C}$, The top ten food categories with increased intakes by participants. Right: $\square$, restricted food materials by COVID-19; active change to prevent COVID-19

background, disease history, degree of attention paid to the epidemic, degree of attention paid to nutrition and immunity knowledge and place of residence during the epidemic were the main factors affecting food safety and nutrition $\mathrm{K}$ A-P. In addition, the COVID-19 epidemic has also restricted the food access and choice of some residents.

With the progress of society and the improvement of living standards, people pay more and more attention to food safety and nutrition. The outline of the 'Healthy China 2030' plan also takes promoting and improving food safety and nutrition status of Chinese residents as an important content and goal ${ }^{(10)}$. Researches have shown that food safety and nutrition knowledge interventions can effectively improve people's understanding of relevant knowledge, thereby promoting positive changes in attitudes and practices $^{(11,12)}$. In addition, the education of relevant knowledge is an effective way to improve the awareness rate of relevant knowledge and promote the residents to adopt a healthy lifestyle ${ }^{(13)}$. There is limited research on whether a major public health emergency, such as the epidemic of COVID-19 infection, will affect people's knowledge, attitudes and practices in relation to food safety and nutrition. Our survey found that during the epidemic period, residents had a high awareness rate of most nutrition knowledge, and a high proportion of residents changed their food safety and nutrition-related practices, including active increase in the intakes of vegetables, fruits and water and decrease in the intakes of sugary drinks and snacks. We think public education on various media and platforms contributed to these changes, as the attention paid to nutrition and immunity knowledge was significantly associated with food change score in the present study. At the same time, it is also suggested that during major public health emergencies, it is of great significance to address biased or misleading information, correctly and actively guide public opinions and it can bring a broader impact. We should take this opportunity to further strengthen the education on the safe and healthy lifestyles to the residents at a time when people are paying more attention and concern.

With the development of modern communications and information technology, the residents have more access to 
Table 5 Logistic regression analysis of associated factors of food change score

\begin{tabular}{|c|c|c|c|}
\hline Variable & OR & $95 \% \mathrm{Cl}$ & $P$ value \\
\hline \multicolumn{4}{|l|}{ Gender } \\
\hline Male & - & & - \\
\hline Female & $1 \cdot 123$ & $0.912,1.384$ & 0.275 \\
\hline Age & 1.020 & $1.007,1.033$ & 0.003 \\
\hline \multicolumn{4}{|l|}{ Education background } \\
\hline High school or below & - & & - \\
\hline Associate degree & 1.028 & $0.707,1.494$ & 0.110 \\
\hline Bachelor degree & 0.970 & $0.679,1.387$ & 0.869 \\
\hline Master degree and & $1 \cdot 187$ & $0.769,1.831$ & 0.439 \\
\hline \multicolumn{4}{|l|}{ With medical background or not } \\
\hline No & - & & - \\
\hline Yes & 0.896 & $0.688,1.168$ & 0.418 \\
\hline \multicolumn{4}{|l|}{ Medical history } \\
\hline No & - & & - \\
\hline Yes & $1 \cdot 110$ & $0.799,1.541$ & 0.534 \\
\hline \multicolumn{4}{|l|}{ Attention to COVID-19 } \\
\hline Basically not involved & - & & - \\
\hline 3-5 times/week, $<20 \mathrm{~min} / \mathrm{time}$ & 1.071 & $0.645,1.777$ & 0.792 \\
\hline$<20 \mathrm{~m}$ & $1 \cdot 312$ & $0.7 \varepsilon$ & 0.296 \\
\hline $20-4$ & 1.359 & $0.806,2 \cdot 293$ & 0.250 \\
\hline $40-60 \mathrm{~min} / \mathrm{d}$ & 1.091 & $0.612,1.944$ & 0.767 \\
\hline $1-2 \mathrm{~h} / \mathrm{d}$ & $1 \cdot 734$ & $0.975,3.081$ & 0.061 \\
\hline More than $2 \mathrm{~h} / \mathrm{d}$ & 1.600 & $0.888,2.883$ & 0.118 \\
\hline \multicolumn{4}{|l|}{$\begin{array}{l}\text { Attention to nutrition and immunity } \\
\text { knowledge }\end{array}$} \\
\hline No attention & - & & - \\
\hline Passi & $1 \cdot 321$ & $1.096,1.592$ & 0.003 \\
\hline Active attention & $1 \cdot 204$ & $1 \cdot 105,1.312$ & 0.002 \\
\hline \multicolumn{4}{|l|}{$\begin{array}{l}\text { Place of residence during } \\
\text { COVID-19 outbreak }\end{array}$} \\
\hline First-ti & - & & - \\
\hline Other cities & 1.496 & $1 \cdot 280,1 \cdot 749$ & $<0.001$ \\
\hline
\end{tabular}

information nowadays. In our study, the channels they chose most were official Weibo/WeChat/Public Account, followed by the mainstream media (e.g. Xinhua News Agency/CCTV/People's Daily), then various news client news feeds and WeChat/personal microblog/Dou Yin. In addition, residents' knowledge, attitudes and practices were also associated with gender, age, educational background, professional background, health status and living area. Therefore, food safety and nutrition education must also comprehensively consider the above-mentioned related factors. We should adopt more diversified methods and approaches for different populations. For example, the Chinese nutrition society has conducted popular science lectures on WeChat, Douyin, CCtalk and other platforms, in addition to the mainstream media channels ${ }^{(8,9)}$.

There are some limitations in our study. First, since in such a special period, all participants were isolated at home, we could only get information through online questionnaire using a snowball sampling method which led to selection bias. Most of our participants were young women with a medical background. They probably paid more attention to epidemic situation and had good knowledge and attitudes towards food safety and nutrition because of professional backgrounds. This suggested that the food safety and nutrition K-A-P of participants in our study were probably better than the actual average level of the whole population. Second, participants with a bachelor's degree or above had lower scores of food safety practices than those with high school degree or below, although they had higher scores of knowledge and attitudes. We could not analyse the reason of this phenomenon based on our data. We speculated that it was probably because that participants with higher education were more objective and rational about the COVID-19 epidemic situation and were not easy to change their practices deliberately.

In conclusion, during the epidemic of COVID-19, the overall situation of participants' food safety and nutrition $\mathrm{K}-\mathrm{A}-\mathrm{P}$ is good in the present study, but there is still room for improvement. The public education of food safety and nutrition should be promoted as a regular work and more widely implemented in various units and departments at the grass-roots level. Through a variety of flexible methods and channels, healthy living information could be more accessible to the general public in more fields.

\section{Acknowledgements}

Acknowledgements: Not applicable. Financial support: Not applicable. Conflict of interest: There are no conflicts of interest. Authorship: Y.L.: Collect data/analyse the data/ statistical analysis/draft articles. L.C.: Implementation research/critical review of the content of the article/guide the work. F.X.: Collect data/critical review of the content of the article/support work. X.G.: collect data/administrative, technical or material support. D.H.: collect data/critical review of the content of the article/support work. L.N.: study design/implementation research/draft articles/guide the work. Ethics of human subject participation: This study was conducted according to the guidelines laid down in the Declaration of Helsinki, and all procedures involving research study participants were approved by the ethics committee of Shanghai University of Medicine \& Health Sciences. Written informed consent was obtained from all subjects.

\section{References}

1. Phelan AL, Katz R \& Gostin LO (2020) The novel coronavirus originating in Wuhan, China: challenges for Global Health Governance. JAMA. Published online: 31 January 2020. doi: 10.1001/jama.2020.1097.

2. Wu F, Zhao S, Yu B et al. (2020) A new coronavirus associated with human respiratory disease in China. Nature. Published online: 6 February 2020. doi: 10.1038/s41586020-2008-3.

3. Lu ZL, He RY, Jiang WY et al. (2020) Clinical characteristics and immune function analysis of COVID-19. Med J Wuban Univ. Published online: 20 March 2020. doi: 10.14188/j. 1671-8852.2020.0126.

4. Nutrition Management in Critically Ill Project Team, Chinese Nutrition Society for Clinical Nutrition (2020) Recommendations for nutrition therapy in critically ill 
COVID-19 patients [J/OL], 1-8. http://kns.cnki.net/kcms/ detail/31.1794.R.20200311.0958.002.html (accessed March 2020).

5. Chinese Nutrition Society, Chinese Medical Doctor Association, Chinese Medical Association of Parenteral and Enteral Nutrition (2020) Nutritional diet guidance for prevention and treatment of pneumonia caused by new coronavirus infection. http://www.nhc.gov.cn/sps/s7886/202002/a69fd 36d54514c5a9a3f456188cbc428.shtml?from=timeline (accessed February 2020).

6. Chinese Nutrition Society (2020) Nutrition and Diet Guidance During Period of Anti COVID-19, 1st ed. Tsinghua University Press. http://www.tup.tsinghua.edu. $\mathrm{cn} /$ booksCenter/booklist.html?keyword=9787302550181 \&keytm $=8$ E3532269285906C89 (accessed March 2020).

7. Clinical Nutrition Branch of Chinese Society of Nutrition (2020) Nutritional suggestions for prevention and therapy of novel coronavirus pneumonia. https://www. cnsoc.org/scienpopuln/122000201.html (accessed February 2020).
8. Chinese Nutrition Society (2020) Series of public welfare micro courses: Nutritional Guidance for Prevention and Therapy of Novel Coronavirus Pneumonia. Platform: CCtalk. https://www.thepaper.cn/newsDetail_forward_ 6099586 (accessed February 2020).

9. Chinese Nutrition Society (2020) Douyin "Nutrition Speaker". https://www.cnsoc.org/learnnews/322000200.html (accessed February 2020).

10. Chao Z \& Juan L (2016) The State Council of the CPC Central Committee printed and distributed "the Outline of Healthy China 2030". Bull State Council People's Republic of China 32, 5-20.

11. Yaping L, Junmei D, Ying B et al. (2017) Intervention of food safety and nutrition knowledge and its effect among Catering staff. China Med Herald 14, 189-192.

12. Xiulin Y (2012) Influence of nutritional intervention in the KAP of housewives. Mod Prev Med 39, 3868-3873.

13. Bingqin L (2018) Primary thinking about the ground and pathway of food nutrition and safety knowledge popularization in China. Farm Prod Process 5, 99-100. 